\title{
Assessment of different coastal defence structures to promote wave energy dissipation and sediments retention
}

\author{
B. F. V. Vieira ${ }^{1}$, J. L. S. Pinho ${ }^{1}$ and J. A. O. Barros ${ }^{1}$ \\ ${ }^{1}$ University of Minho, Portugal \\ barbaravasquezvieira@gmail.com
}

\begin{abstract}
Coastal areas are an apprized environment by society that will continue to expand rapidly. Traditional coastal protection structures are commonly deployed to protect coastal areas endangered by natural extreme weather events. However, due to their limited efficiency and very high costs, more efficient and sustainable strategies to deal with coastal erosion are imperative.

This research work focuses on the assessment of engineering solutions to mitigate and delay coastal erosion. Three different structure geometries (triangular prism shape, single detached breakwater and group of two detached breakwaters) are analysed on a realistic bathymetry, using a combination of numerical models (SWAN and XBeach) to study the influence of those structures on the coastal hydro- and morphodynamics. SWAN was used for hydrodynamics and XBeach for hydrodynamics and morphodynamics assessments. In addition, a comparison between SWAN and XBeach hydrodynamics results was also performed.

Structures considered in this study have regular shaped geometries, and are characterized in terms of their efficiency regarding wave height and wave energy dissipation considering different wave regimes and performance in terms of longterm beach morphodynamic impact (sediments accumulation and erosion). The analysis is concentrated in two scenarios, one for low and the other for highly energetic hydrodynamics (the most challenging to coastal zones defence). The obtained results allowed classifying their performance in terms of the impact on wave energy and wave height dissipation, and sediment erosion/deposition patterns.
\end{abstract}

Keywords: Hydrodynamics, Morphodynamics, Numerical modelling, Coastal structures

\section{Introduction}

Coastal areas are a much-appreciated environment by society, and support a large amount of economic and leisure activities [1]. Due to coastal ecosystems vulnerability to natural and anthropogenic hazards, a range of challenges, including coastal erosion and rapid urbanization are contributing to their environmental degradation [2]-[4].

Projections presented by the Intergovernmental Panel on Climate Change (IPCC) indicate that global climate change may rise sea level, and, in some areas, increase the frequency and severity of storms [5]. Coastal protection on zones prone to shoreline 
retreat due to high tide/wave energy action and high sediment transport deficit may involve different solutions to control coastal erosion. However, traditional hard structures are not necessarily the most adequate solution since they can generate adverse effects such as: aggravation of erosion downdrift; disturbance of sediment supply and beach reduction; and adverse visual impacts [6], [7]. Coastal defence structures should contribute to the dissipation of wave energy before reaching the beach, minimizing, this way, erosion. It is important to highlight that the implementation of coastal structures may locally reduce risks of exposure to sea action, but does not eliminate them, and these should not be used as an excuse to allow building in areas of risk.

Behind the search for more efficient and sustainable strategies to deal with coastal retreat, this study focuses on a comparison between the performance of two traditional coastal protection solutions (single detached breakwater and group of two detached breakwaters) and a different structure shape on a particular coastal stretch. In order to analyse the hydro- (wave height and wave energy dissipation) and morphodynamics (sediments accumulation and erosion areas) of the structures and beach interactions, two computer programs were used: SWAN [8] for hydrodynamics and XBeach [9] for hydrodynamics and morphodynamics. In addition, a comparison between SWAN and XBeach hydrodynamics results was also performed, using three SWAN models for each one of the assessed structures and three XBeach models for the same structures.

\section{Methodology}

\subsection{SWAN and XBeach numerical models}

SWAN (Simulation WAves Nearshore) can be used as stand-alone application, but it is also included in the Delft3D 4 Suite [10]. SWAN [8] is a spectral wave model for obtaining realistic estimates of wave propagation in coastal areas, lakes and estuaries. The model is based on the wave action balance equation, and simulates the wave propagation from deep waters to the transition zone considering the physical processes of refraction, diffraction, shoaling, currents interaction, wave growth by wind action, wave breaking under the influence of excess slope, power dissipation due to bottom friction, blocking and reflection by opposing currents and transmission through obstacles. The spread of wave propagation in stationary or non-stationary modes, in the geographical and spectral spaces is performed using implicit numerical schemes. The data required for the implementation of SWAN are bathymetry of the model area and wave conditions at the open boundaries. Among the several results obtained by SWAN, these are the ones that stand out: significant wave heights $\left(\mathrm{H}_{\mathrm{s}}\right)$, peak and average time periods (T), peak and average directions, directional dispersion, and level of water anywhere in the computational domain [11]. The application of SWAN at ocean scales is not recommended from an efficiency point of view. SWAN does not calculate wave-induced currents, and is not applicable to shallow waters (it is only valid to deep and transitional waters). 
XBeach [9] numerical model is used for the computation of 2D-horizontal nearshore hydrodynamics due to wave propagation, including surf-beat (long period waves), average flow, and wave-induced currents in combination with non-cohesive sediment transports, overwash (wave uprush over a natural or artificial coastal barrier), scour around hard structures, and morphological changes of the nearshore beaches and dunes during storm events. XBeach concurrently solves the time-dependent short wave action balance, the roller energy equations, the nonlinear shallow water equations (NSWE) of mass and momentum, the sediment transport and bed change equations. As boundary conditions, XBeach requires tidal levels, deeper-water (outside the surf zone) wave conditions and bathymetry [12]. Users are allowed to choose which mode options to implement: stationary wave mode, surf-beat mode (instationary), and non-hydrostatic mode (wave-resolving: the most computationally expensive mode, because it requires higher spatial resolution and associated smaller time steps) [13]. Further information on these modes can be consulted in [14]. The model accounts for feedback between the evolving bathymetry and the hydrodynamics at each time step.

\subsection{Simulated Scenarios}

For this study, three different geometries for coastal protection structures were analysed. For better understanding the performance of a different shaped structure (Fig. 1a), the impact of this structure on a coastal zone was compared with a typical detached breakwater (Fig. 1b) and a group of detached breakwaters (Fig. 1c). The case study developed by [15] is taken as a reference for the modelling of the different shaped structure that resembles a triangular prism, where the structure performance was conducted in terms of 'surfability' and coastal protection. [15] analysed the performance of two triangular prism structure geometries differing in their opening angles $\left(45^{\circ}\right.$ and $66^{\circ}$ ) for two different incident wave conditions (frequent wave: $\mathrm{H}_{\mathrm{s}}=1.5, \mathrm{~T}=9 \mathrm{~s}$; and storm wave: $\mathrm{H}_{\mathrm{s}}=4, \mathrm{~T}=15 \mathrm{~s}$ ) and concluded that both geometries contribute to sedimentation. For the current study, results analysis will focus on coastal protection purposes and it will consider the structure geometry of $45^{\circ}$ opening angle due to its wider shadow zone benefits for coastal protection. As geometrical considerations, all structures share the same length $(250 \mathrm{~m})$, except the two detached breakwaters in Fig. 1c that presents a third of the length considered in the other structures $(83 \mathrm{~m})$. The detached breakwaters were designed to have a crest width of $10 \mathrm{~m}$ and side-slopes of 1:2, which are representative of regular structures of this type as presented in [16]. The triangular prism structure followed [15] design with a crest width of $75 \mathrm{~m}$ and side slopes of 1:10. All structures have their crests submerged at $-1.5 \mathrm{~m}$ relatively to mean sea level and are located at the same distance from the shoreline $(440 \mathrm{~m})$.

In order to study the structure's influence on significant wave heights attenuation and sediments accumulation, a realistic bathymetry was used for the model simulations, based on [15]'s study. Regarding model conditions, the computational domain is $1670 \mathrm{~m} \times 1870 \mathrm{~m}$ (crosshore $\times$ longshore) with a node spacing of $\mathrm{dx}=\mathrm{dy}=5.0 \mathrm{~m}$ for both hydro- and morphodynamics analysis. The total simulation time was two hours for the hydrodynamics analysis (using SWAN and XBeach) and one day for morphodynamics 
(XBeach) with a morphological acceleration factor to speed up the morphological time scale relative to the hydrodynamic timescale (morfac) of 50.

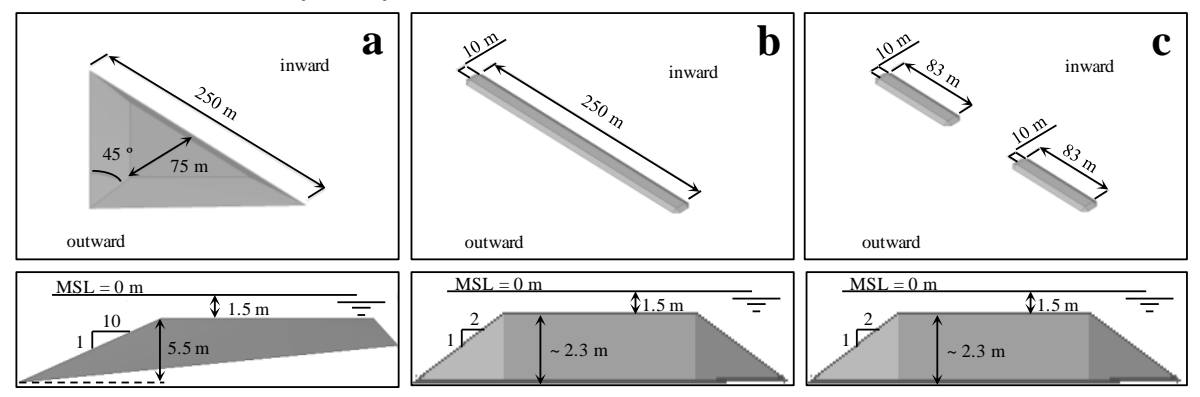

Fig. 1 Geometrical shapes considered in this study (upper panel: plan view; lower panel: cross-section): a) triangular prism structure; b) regular detached breakwater; c) group of detached breakwaters.

The study by [17] on the simulation time for morphodynamics has concluded that the necessary time (in days) to study the morphological development process of a significant salient due to a detached breakwater placed $500 \mathrm{~m}$ away from the shoreline was seventy-five days with a morfac equal to 100 (approximately twenty years). Even though the simulation time considered in this study is significantly shorter than the [17]'s (justified by the need to reduce calculation time), it is adequate to study the sediments transport tendency to erosion or accretion.

For hydrodynamics (using SWAN and XBeach), the frequent wave and the storm wave conditions considered in [15] were adopted in this study, with waves incoming from the West direction $\left(270^{\circ}\right)$, while the tide level considered was $0 \mathrm{~m}$ (mean sea level). For morphodynamics analysis (using XBeach), only the frequent wave scenario was analysed, in order to give insights on the response to a mean wave climate. Regarding seabed composition, the sediments dimensions considered were $200 \mu \mathrm{m}$ for $\mathrm{D}_{50}$ and $300 \mu \mathrm{m}$ for $\mathrm{D}_{90}$, being $\mathrm{D}_{50}$ and $\mathrm{D}_{90}$ common metrics used to describe particle size distributions. In this case, $\mathrm{D}_{50}$ means that $50 \%$ of the sample has a size of $200 \mu \mathrm{m}$ or smaller and $\mathrm{D}_{90}$ that $90 \%$ has a size of $300 \mu \mathrm{m}$ or smaller. Boundary conditions for SWAN model (hydrodynamics) were defined for North, West and South boundaries (frequent and storm wave conditions), while for XBeach model (hydrodynamics and morphodynamics) absorbing-generating (weakly-reflective) boundary in 2D (abs_2d) for front and back boundaries, and wall boundary condition (simple no flux boundary condition) for left and right boundaries were defined. In XBeach model the left and right designations correspond to North and South, while front and back to West and East, respectively.

For hydrodynamics (SWAN and XBeach), the wave type considered was a JONSWAP spectrum, whereas for morphodynamics (XBeach) the stationary mode was selected. The consideration of stationary mode is justified by the need to reduce model calculation time for morphodynamics. The numerical model results obtained by the SWAN model are the significant wave heights, while XBeach model estimates the sediments accumulation and erosion near shoreline as well as the bed level. XBeach presents $H_{r m s}$ values (root mean square wave heights), which require a conversion to $H_{s}$ 
(significant wave heights), in order to be compared to SWAN hydrodynamics results. The wave energy dissipation also requires separate calculation.

\section{$3 \quad$ Results and discussion}

\subsection{Hydrodynamics}

Numerical simulations for the analysis of significant wave heights dissipation for two different scenarios (frequent wave and storm wave conditions) were performed for each structure: triangular prism structure (Figs. 2a1 and 2a2), detached breakwater (Figs. 2b1 and 2b2) and group of detached breakwaters (Figs. 2c1 and 2c2). Comparatively to a situation without structure, an analysis of the influence of each structure on the significant wave heights on a storm wave condition was also performed (Figs. 2a3, $2 \mathrm{~b} 3$ and 2c3). For a more legible analysis, the presented results are centred in a limited window around the structures. The contour lines are also depicted in all presented results.

From the results presented in Fig. 2, wave shoaling (increase of the wave height) in every structure shape is evident due to a decrease of the depth. This phenomenon is visible at the apex of the triangular prism structure for both wave conditions (represented with number 1 in Figs. 2a1 and 2a2); at the North extremity of the detached breakwater and group of detached breakwaters for the storm wave condition (represented with number 2 in Figs. $2 \mathrm{~b} 2$ and 2c2); a small wave shoaling along the detached breakwater for both wave conditions (represented with number 3 in Figs. $2 \mathrm{~b} 1$ and $2 \mathrm{~b} 2$ ), and also a small wave shoaling along the group of detached breakwaters for both wave conditions (also represented with number 3 in Figs. 2c1 and $2 \mathrm{c} 2$ ). A more intense variation of bottom elevation due to the presence of the detached breakwaters near the North extremities, relatively to the South extremities, may explain the wave shoaling at this particular area (2). The most evident wave shoaling is at the apex of the triangular prism structure (1), while on the other mentioned cases ( 2 and 3 ) the differences are more subtle. Regarding significant wave heights decrease, it is clear the effect for every structure shape under both wave conditions. This dissipation is more significant for the storm wave condition. For the triangular prism structure, a progressive increase on significant wave heights is visible from the structure inward (protected) extremity to position $1.45 \mathrm{~km}$ for frequent wave condition (represented with number 4 in Fig. 2a1) and $1.28 \mathrm{~km}$ for storm wave condition (also represented with number 4 in Fig. 2a2). After the position $1.28 \mathrm{~km}$ for storm wave condition, the significant wave heights progressively decrease towards shoreline. These phenomena are explained by the shoaling and breaking due to depth decrease. For the detached breakwater this phenomenon is not visible for the storm wave condition, but it is present for the frequent wave where an increase of significant wave height is perceptible from the structure inward extremity to position $1.42 \mathrm{~km}$ (also represented with number 4 in Fig. 2b1). From this position towards shoreline, the significant wave heights decrease gradually. 

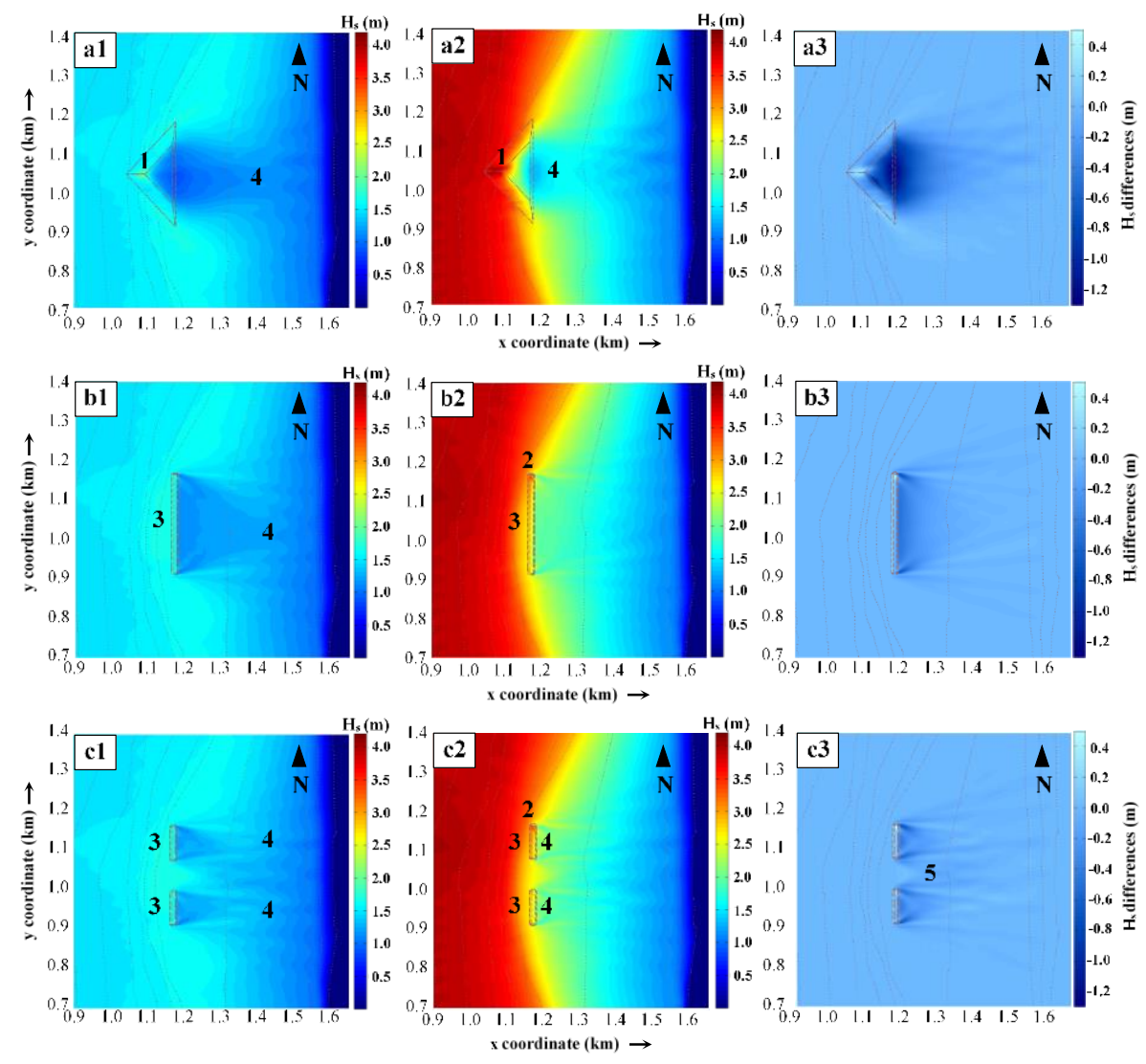

Fig. 2 Significant wave heights dissipation for frequent wave condition: triangular prism structure (a1); detached breakwater (b1), and group of detached breakwaters (c1); and storm wave condition: triangular prism structure (a2), detached breakwater (b2), and group of detached breakwaters (c2). Significant wave heights difference with and without any structure on a storm wave condition: triangular prism structure (a3), detached breakwater (b3), and group of detached breakwaters (c3).

Finally, for the group of detached breakwaters a small increase on the significant wave height is visible from the structure inward extremity to position $1.21 \mathrm{~km}$ for the storm wave condition (also represented with number 4 in Fig. 2c2), and also an increase of significant wave height from the structure inward extremity to position $1.42 \mathrm{~km}$ for the frequent wave condition (also represented with number 4 in Fig. 2c1). After those positions, the significant wave heights decrease towards shoreline. Results for the North and South detached breakwater from the group of detached breakwaters are similar.

Relatively to the influence of a structure on significant wave heights, it is clear that all structures contribute to a decrease and that the triangular prism structure reduces significant wave heights at a larger scale (Fig. 2a3) than the detached breakwater and group of detached breakwaters. On the group of detached breakwaters, even though there is a gap between the structures, a small significant wave 
height reduction at the inward side is observable in Fig. 2c3 (represented with number 5). Near the shoreline, although the three cases (Figs. 2a3, 2b3 and 2c3) do not present any significant differences, it can be concluded that the triangular prism structure presents a more significant and larger shadow zone than the other two solutions. This effect can bring protection benefits if the structure is positioned closer to shoreline.

The XBeach numerical results for root mean square wave heights $\left(\mathrm{H}_{\mathrm{rms}}\right)$ were converted to significant wave heights $\left(H_{s}\right)$ using Eq. (1) [18].

$$
H_{s}=\sqrt{2} \times H_{r m s}
$$

The plots depicted in Fig. 3 present the similarities and differences between the significant wave heights results for SWAN and XBeach. The plots show the results for a cross-section at each structure. Results for the South detached breakwater from the group of detached breakwaters are not presented in this study due to results similarity to the North structure. The indicated values in the plots were selected for four positions: before, immediately before, immediately after and after the structures. The vertical lines plotted represent relevant seabed slope changes.

As mentioned before, the wave shoaling due to a sudden depth change immediately before the structure is visible for all cases with both numerical models. From the analysis of Fig. 3, it is clear that both SWAN and XBeach simulate this phenomenon for all structures and that for the all storm wave conditions, SWAN simulates a small wave shoaling due to the slope change at positions $625 \mathrm{~m}$ and $1125 \mathrm{~m}$, and a wave shoaling for all frequent wave condition at position $1125 \mathrm{~m}$. The XBeach model only represents a significant wave shoaling for the frequent and storm wave condition for the triangular prism structure at position $1125 \mathrm{~m}$.

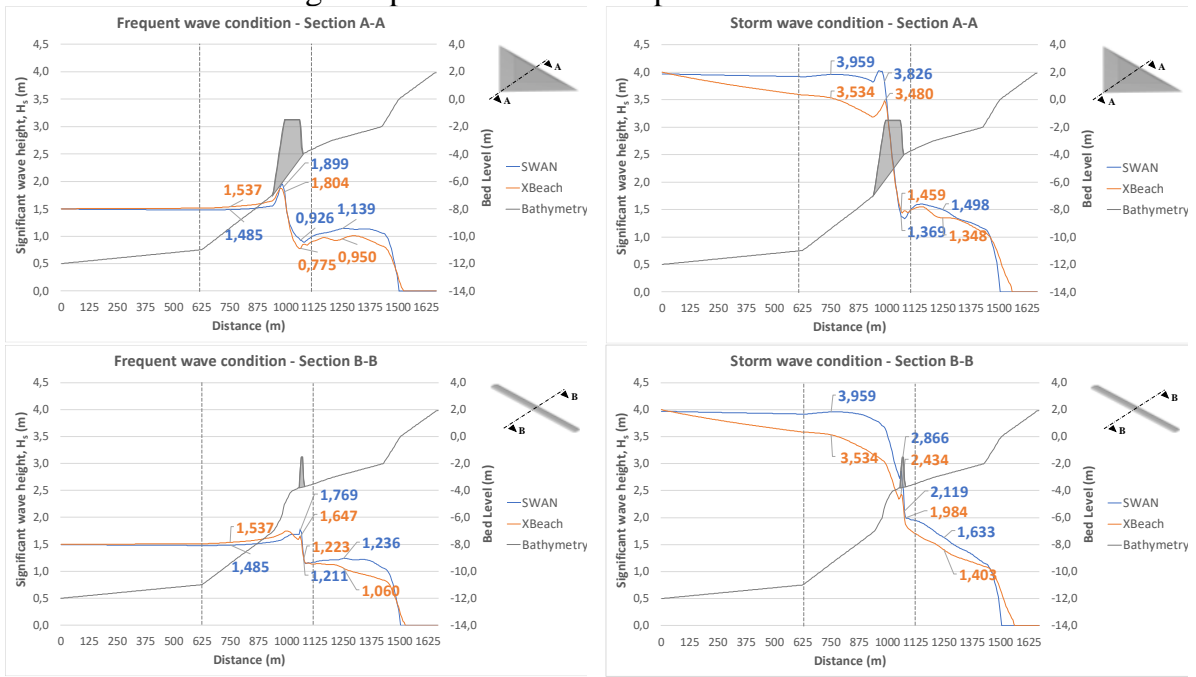



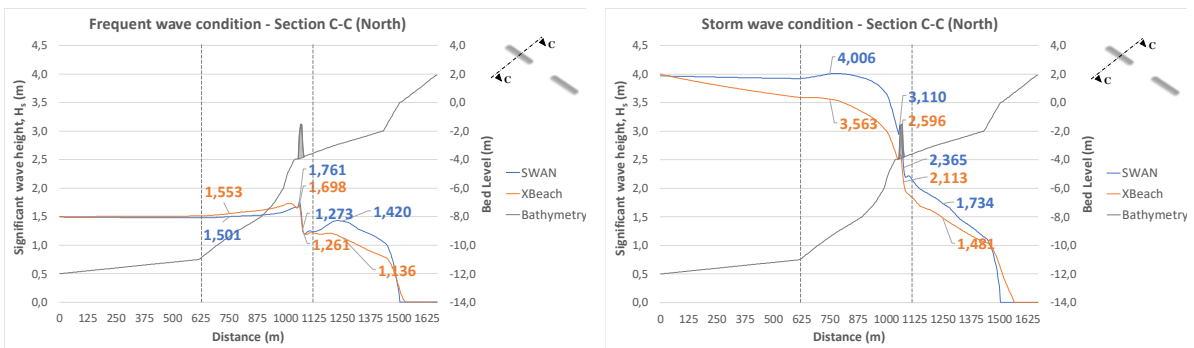

Fig. 3 Comparison between SWAN and XBeach significant wave height results for frequent $(\mathrm{Hs}=1.5 \mathrm{~m}, \mathrm{~T}=9 \mathrm{~s})$ and storm $(\mathrm{Hs}=4 \mathrm{~m}, \mathrm{~T}=15 \mathrm{~s})$ conditions for: triangular prism structure (Section $\mathrm{A}-\mathrm{A})$, detached breakwater (Section B-B) and North detached breakwater from the group of detached breakwaters (Section C-C).

Eqs. (2), (3) and (4) were, respectively, applied in order to proceed to: an overall comparison between SWAN and XBeach hydrodynamics results $(\Delta)$; an overall percentage of significant wave height results reduction before and after the structures for both wave conditions $(\alpha)$; and their wave energy reduction results $(\beta)$. Eq. (5) represents the wave energy equation (E) used for this study.

$$
\begin{gathered}
\Delta_{\text {SWAN-XBeach }}=H_{\text {S SWAN }}-H_{\text {SBBeach }} \\
\alpha=\left(H_{\text {SBefore }}-H_{\text {SAfter }}\right) / H_{\text {SBefore }} \times 100 \\
\beta=\left(E_{\text {Before }}-E_{\text {After }}\right) / E_{\text {Before }} \times 100 \\
E=\frac{1}{8}\left(\rho g H^{2}\right)
\end{gathered}
$$

where $\Delta_{\text {SwAN-XBeach }}$ is the comparison between significant wave height results between both models for a specific location (m); $\mathrm{H}_{\mathrm{s}}$ SWAN and $\mathrm{H}_{\mathrm{s}}$ XBeach are the significant wave height computed by, respectively, SWAN and XBeach model for a specific location (m); $\alpha$ is the numerical model $\mathrm{H}_{\mathrm{s}}$ reduction for a specific location (\%); $\mathrm{H}_{\mathrm{s} \text { Before }}$ and $\mathrm{H}_{\mathrm{s}}$ After are the significant wave height, respectively, before and after, a structure (m); $\beta$ is the numerical model $\mathrm{E}$ reduction for a specific location (\%); $\mathrm{E}_{\text {Before }}$ and $\mathrm{E}_{\mathrm{After}}$ are the wave energy, respectively, before and after, a structure $\left(\mathrm{J} / \mathrm{m}^{2}\right)$; E is the wave energy per unit area $\left(\mathrm{J} / \mathrm{m}^{2}\right) ; \rho$ is the water density $\left(\mathrm{kg} / \mathrm{m}^{3}\right) ; \mathrm{g}$ is the gravity acceleration $\left(\mathrm{m} / \mathrm{s}^{2}\right)$; and $\mathrm{H}$ is the wave height $(\mathrm{m})$. Considering $\rho_{\text {seawater }}=1025 \mathrm{~kg} / \mathrm{m}^{3}$ and $\mathrm{g}=9,81$ $\mathrm{m} / \mathrm{s}^{2}$ the wave energy was computed for all scenarios.

From Fig. 3 and using Eq. (2), it is clear that for the frequent wave condition, the SWAN results before the structures (triangular prism; detached breakwater; and group of detached breakwaters) calculates smaller significant wave heights than the XBeach model $(-0.05 ;-0.05 ;-0.05)$, and greater significant wave heights after the structures $(0.19,0.18,0.28)$. For the storm wave condition, SWAN model computes greater significant wave heights than the XBeach model before $(0.42 ; 0.42 ; 0.44)$ and after $(0.15 ; 0.23 ; 0.25)$ the structures.

Regarding the difference between significant wave heights before and after the structures, using Eq. (3), XBeach presents greater reduction values than the SWAN 
model. Similar reduction values for significant wave height (SWAN, XBeach) can be seen for the storm wave conditions $[(62.16 \%, 62.85 \%)$; $(58.75 \%, 60.30 \%)$; $(56.71,58.43 \%)]$, while for the frequent wave condition significant differences are evident $[(23.30 \%, 38.21 \%) ;(16.77 \%, 31.00 \%) ;(5.40 \%, 26.84 \%)]$ (triangular prism; detached breakwater; and group of detached breakwaters). For both scenarios, the triangular prism structure has the best performance, due to higher reduction values, whereas the group of detached breakwater is the least effective.

Overall, for extreme wave conditions, results for significant wave height reductions for both SWAN and XBeach models are similar, which indicates that, even though the significant wave heights calculated are different, the performance for each structure is comparable. Since wave energy is proportional to wave heights (Eq. (5)), the same conclusion for wave energy can be taken (Eq. (4)).

\subsection{Morphodynamics}

One of the suggestions proposed by [15] was to study morphodynamics around the structure to enable a deeper understanding on sedimentation and erosion areas. In order to develop that study, XBeach morphodynamic models for each one of the structures were performed. Also, a study developed by [17] where the XBeach model was used to analyse salient and tombolo formations for different detached breakwater conditions was considered for testing the results quality and ensure the adequate models conditions.

Numerical simulations for the analysis of cumulative sedimentation and erosion for the frequent wave condition were conducted for each shape: triangular prism structure (Fig. 4a1), detached breakwater (Fig. 4b1) and group of detached breakwaters (Fig. 4c1). Figs. 4a2, $4 \mathrm{~b} 2$ and $4 \mathrm{c} 2$ show the bed level evolution at the end of the XBeach simulation for each structure shape. The study was performed for one day with a morfac of 50, which insights results for fifty days. The simulations were taken for a frequent wave condition and the results presented are cropped for a more legible analysis. From the results depicted in Figs. 4a1, 4b1, and 4c1, it is evident the most significant erosion areas immediately after the triangular prism structure (1) (over $-0.9 \mathrm{~m}$ ); outwards the detached breakwater and group of detached breakwaters (2) due to waves reflection $(-0.1 \mathrm{~m})$; at the North and South extremities of the detached breakwater and group of detached breakwaters (3) due to waves diffraction $(-0.1 \mathrm{~m})$; and downdrift near the shoreline of all the three structures (4) (-0.3m). Along the shoreline, a very small erosion with the same magnitude $(-0.1 \mathrm{~m})$ for the three scenarios is also evident. Outwards the triangular prism structure (5), it is also noticeable a slight erosion due to waves reflexion $(-0.1 \mathrm{~m})$. Regarding the erosion on the detached breakwater and group of detached breakwaters (marked with numbers 2 and 3), it is noticeable a more intense phenomenon on the detached breakwater scenario. These erosion areas near the structures may put at risk the structures stability due to scouring. Near the shoreline, the downdrift erosion on the detached breakwater and group of detached breakwaters scenarios (4) is slightly more intense than the erosion in the triangular prism structure scenario (4). In the group of detached breakwaters there is no erosion at the gap between the structures. 

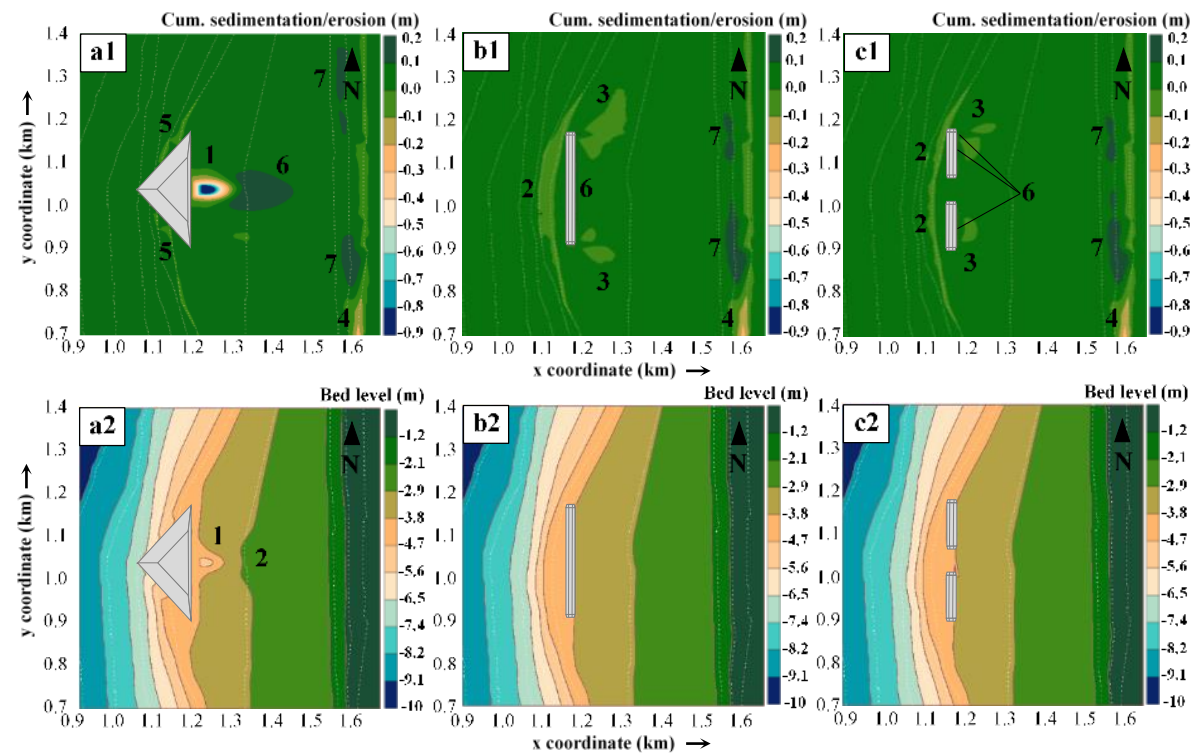

Fig. 4 Cumulative sedimentation and erosion for frequent wave condition: triangular prism structure (a1); detached breakwater (b1), group of detached breakwaters (c1). Bed level for frequent wave condition: triangular prism structure (a2); detached breakwater (b2), group of detached breakwaters (c2).

Regarding sedimentation areas, it is visible a significant sediments accretion of $0.2 \mathrm{~m}$ inwards the triangular prism structure (6) immediately after the erosion area, which may suggest that part of the sediments on the eroded area settled further ahead. Along the shoreline, in the triangular prism structure there is a significant sedimentation updrift and downdrift the structure (7) $(0.2 \mathrm{~m})$, while on the detached breakwater and group of detached breakwaters the corresponding sedimentation (7) is located at the structures protected region. Immediately after the detached breakwater and group of detached breakwaters (6) there is also a slight sediments accretion $(0.2 \mathrm{~m})$. From the results presented in Figs. $4 \mathrm{a} 2,4 \mathrm{~b} 2$, and $4 \mathrm{c} 2$, it can be concluded that there were no significant changes in morphology in all scenarios, except for immediately after the triangular prism structure (Fig. 4a2) where the erosion (1) and sedimentation (2) phenomena altered the bed level.

\section{Conclusions}

This study aimed to assess the performance of a triangular prism structure and two traditional coastal protection solutions in dissipating wave energy and protecting the beach using numerical models implemented with SWAN and XBeach. In addition, a comparison between SWAN and XBeach hydrodynamics results was also performed. The triangular prism structure characteristics were based on a previous [15] research work, and all structures analysed were simulated for storm and frequent wave conditions. Regarding significant wave heights results, a substantial decrease 
between before and after every structure shape is clear for both wave scenarios (especially during storm wave conditions), which indicates that all structures have great influence on reducing significant wave heights and wave energy. Amongst all structures, for both scenarios, the triangular prism was the best for reducing significant wave heights at a larger scale and a larger shadow zone compared to the detached breakwater and group of detached breakwaters, which can bring protection benefits if the structure is positioned closer to shoreline. The least effective structure is the group of detached breakwaters.

Comparing both models, it can be concluded that, overall, SWAN numerical model tends to present greater significant wave heights results; and that XBeach presents greater percentages of significant wave heights reduction for frequent wave conditions, and similar values for storm wave conditions. This similarity indicates that, even though the significant wave heights calculated are different, the performance for each structure is comparable. The same conclusions can be taken for wave energy results.

Regarding morphodynamics, the obtained results present a favourable tendency to sediments accretion near the shoreline, and at the inward areas for the three structures, since the greatest values for sediments accumulation are located at these sites. The most significant sediments accretion at the shoreline is noticeable for the group of detached breakwaters, while the largest overall sediments accumulation is visible for the triangular prism structure. The accretion and erosion patterns along the shoreline for the three structures scenarios are similar for the fifty days insights. It is important to note that erosion areas near all structures jeopardise their stability due to local scouring. In the simulated numerical models, the widely known erosion effects near the detached breakwaters (simple and group) are evident due to waves reflection and diffraction phenomena. The obtained results suggest that the longer the detached breakwater, the more intense the erosion is near the structure. The largest overall erosion is located inwards the triangular prism structure.

In this study, contrary to [17]'s, patterns of salient formations are not created for these conditions, since there were no evidences of significant changes in bed level results. It is important to mention that the author's study highlighted an emerged structure, which ensures greater sediments retention, and a seventy-five days simulation time. For further studies, emerged structures and/or structures placed closer to shoreline should be better analysed. Also, a longer morphodynamics simulation time and the consideration of a JONSWAP spectrum for the XBeach morphodynamics analysis may present more realistic morphodynamics results.

\section{Acknowledgements}

This work is supported by the Portuguese Foundation for Science and Technology (FCT) [PhD grant number SFRH/BD/141381/2018]. The authors also acknowledge the support provided by the project EcOffShorBe - Eco Offshore Built Environment, n. 37417, R\&D cores in Copromoção, 14/SI/2017, NORTE-01-0247-FEDER-037417, supported by ANI (FEDER). 


\section{References}

[1] B. Castelle, B. Guillot, V. Marieu, E. Chaumillon, V. Hanquiez, S. Bujan, and C. Poppeschi, "Spatial and temporal patterns of shoreline change of a 280-km high-energy disrupted sandy coast from 1950 to 2014: SW France," Estuar. Coast. Shelf Sci., vol. 200, pp. 212-223, 2018, doi: 10.1016/j.ecss.2017.11.005.

[2] P. Narra, C. Coelho, F. Sancho, and J. Palalane, "CERA: An open-source tool for coastal erosion risk assessment," Ocean Coast. Manag., vol. 142, pp. 1-14, 2017, doi: 10.1016/j.ocecoaman.2017.03.013.

[3] United Nations, "Transforming Our World: The 2030 Agenda for Sustainable Development A/RES/70/1," UN General Assembly, 2015.

[4] J. Weinberg, "The Big Squeeze: Coastal megacities face growing pressure from sea and land," Stockholm Waterfront, no. 1, Stockholm, Sweden, pp. 5-7, 2015.

[5] J. Gilbert and P. Vellinga, "Climate Change: The IPCC Response Strategies - Chapter 5," in Report prepared for Intergovernmental Panel on Climate Change by Working Groups III, Digitization and Microform Unit (2010), UNOG Library, 1990, p. 330.

[6] N. Rangel-Buitrago, A. Williams, and G. Anfuso, "Hard protection structures as a principal coastal erosion management strategy along the Caribbean coast of Colombia. A chronicle of pitfalls," Ocean Coast. Manag., vol. 156, pp. 58-75, 2018, doi: https://doi.org/10.1016/j.ocecoaman.2017.04.006.

[7] A. Williams, N. Rangel-Buitrago, E. Pranzini, and G. Anfuso, "The management of coastal erosion," Ocean Coast. Manag., vol. 156, pp. 4-20, Apr. 2018, doi: 10.1016/j.ocecoaman.2017.03.022.

[8] SWAN, "SWAN manual," 2018. [Online]. Available: http://swanmodel.sourceforge.net/online_doc/swanuse/node3.html. [Accessed: 08-Feb2019].

[9] Deltares, “XBeach,” 2019. [Online]. Available: https://www.deltares.nl/en/software/xbeach. [Accessed: 12-Feb-2019].

[10] Deltares, "Delft3D 4 Suite (structured)," 2019. [Online]. Available: https://www.deltares.nl/en/software/delft3d-4-suite. [Accessed: 07-Feb-2019].

[11] R. Capitão and C. Fortes, "Análise comparativa entre estimativas do modelo SWAN e medições de agitação marítima efectuadas na Praia da Amoreira, Portugal," Rev. da Gestão Costeira Integr., vol. 11, no. 3, pp. 283-296, 2011, doi: 10.5894/rgci269.

[12] A. Bolle, P. Mercelis, D. Roelvink, P. Haerens, and K. Trouw, "Application and Validation of Xbeach for Three Different Field Sites.," in Proceedings of 32nd Conference on Coastal Engineering, 30th to 5th July 2010, 2010, pp. 1-14, doi: 10.9753/icce.v32.sediment.40.

[13] D. Roelvink, R. McCall, S. Mehvar, K. Nederhoff, and A. Dastgheib, "Improving predictions of swash dynamics in XBeach: The role of groupiness and incident-band runup," Coast. Eng., vol. 134, pp. 103-123, 2018, doi: https://doi.org/10.1016/j.coastaleng.2017.07.004.

[14] D. J. A. Roelvink, A. van Dongeren, R. McCall, B. Hoonhout, A. van Rooijen, P. van Geer, L. de Vet, K. Nederhoff, and E. Quataert, XBeach Technical Reference: Kingsday Release. 2015.

[15] A. Mendonça, C. J. Fortes, R. Capitão, M. G. Neves, T. Moura, and J. S. Antunes do Carmo, "Wave hydrodynamics around a multi-functional artificial reef at Leirosa," J. Coast. Conserv., vol. 16, no. 4, pp. 543-553, 2012, doi: 10.1007/s11852-012-0196-1.

[16] B. F. V. Vieira, "Wave hydrodynamics in coastal stretches influenced by detached breakwaters," MSc Thesis in Civil Engineering, University of Minho, 2014.

[17] M. S. A. Razak and N. A. Z. M. Nor, "XBeach Process-Based Modelling of Coastal Morphological Features Near Breakwater," MATEC Web Conf., vol. 203, no. 1007, 2018, doi: $10.1051 /$ matecconf/201820301007.

[18] H. Hanson, "Wave transformation," 2019. [Online]. Available: http://www.tvrl.tth.se/fileadmin/tvrl/files/vvr040/3_Wave_transformation_3pp.pdf.

[Accessed: 28-Oct-2019]. 